\title{
Endocrine sequelae beyond 10 years in survivors of medulloblastoma: comparison of three major treatment regimens
}

\author{
S Uday', RD Murray ${ }^{2}$, S Picton ${ }^{3}$, P Chumas ${ }^{4}$, M Rajü ${ }^{3}$, M Chandwani', NS Alvi ${ }^{1}$ \\ 1. Department of Paediatric Endocrinology, Leeds Children's Hospital, Leeds, UK 2. Department of Endocrinology and Diabetes, St James's Hospital, Leeds, UK \\ 3. Department of Oncology, Leeds Children's Hospital, Leeds, UK \\ 4. Department of Paediatric Neurosurgery, Leeds Children's hospital, Leeds, UK
}

\section{Introduction}

Improved survival following treatment for paediatric medulloblastomas has resulted in increased incidence of late effects, particularly endocrine sequelae. The complete picture of late effects, however, has been limited by short duration of follow up

\section{Aims}

To establish the evolution of endocrine sequelae in patients treated for medulloblastoma and to compare the prevalence of endocrine dysfunction among different treatment regimens.

\section{Methods}

Single-centre analysis of medulloblastoma treatment and endocrine sequelae in patients diagnosed between 1982 and 2002.

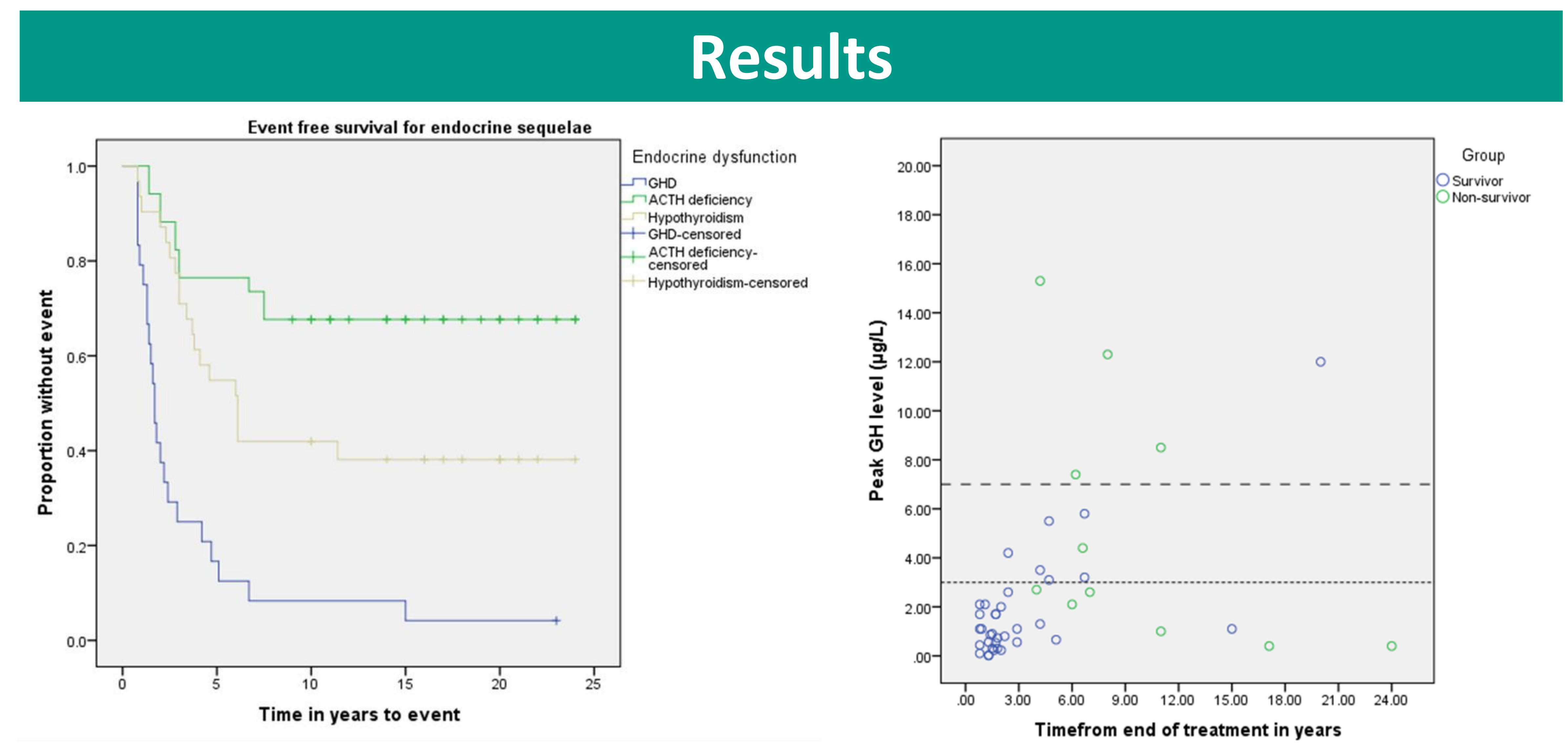

Figure 1: Kaplan-Meier analysis showing proportion of patients with GHD, ACTH deficiency and primary hypothyroidism on a median follow up of 18 years.

Figure 2: Peak growth hormone levels $(\mu \mathrm{g} / \mathrm{L})$ and time from end of treatment at the time of dynamic function test in survivors and non-survivors with and without growth hormone deficiency $(3 \mathrm{mU} / \mathrm{L}=1 \mu \mathrm{g} / \mathrm{L})$

Growth hormone deficiency (GHD) was the most prevalent hormone deficiency (97\%), followed by hypothyroidism (60\%) and adrenocorticotrophic hormone (ACTH) deficiency (45.5\%) (See table). The median time from end of treatment to loss of growth hormone was 1.7 (range 0.7- 15)years; ACTH deficiency 2.9 (range 0.75-7.5)years; and hypothyroidism 4.1 (range 0.7-11.4)years.

\begin{tabular}{|c|c|c|c|c|c|c|}
\hline & $\begin{array}{c}\text { All } \\
\text { survivors } \\
(n=35, \\
\text { males }=25)\end{array}$ & $\begin{array}{c}\text { Baby brain } \\
+R T \\
(n=3 \\
\text { males }=2)\end{array}$ & $\begin{array}{c}\text { CVC+RT } \\
(n=11, \\
\text { males }=10)\end{array}$ & $\begin{array}{c}\text { PNET3 } \\
\text { Chemo } \\
(\mathrm{n}=10, \\
\text { males }=6)\end{array}$ & $\begin{array}{c}\text { PNET3 no } \\
\text { chemo } \\
(n=8, \\
\text { males }=5)\end{array}$ & $\begin{array}{c}\text { Non- } \\
\text { survivors } \\
(n=11, \\
\text { males }=7)\end{array}$ \\
\hline Median age at diagnosis in years & 8 & 2 & 9 & 6.5 & 8.5 & 8 \\
\hline Median follow up in years & 18 & 19 & 12 & 21 & 19 & 7.5 \\
\hline $\begin{array}{l}\text { Complete GH deficiency }(\%) \\
\text { Peak GH }<3 \mu \mathrm{g} / \mathrm{L} \text { in adults and } \\
<7 \mu \mathrm{g} / \mathrm{L} \text { in children }<16 \text { years }\end{array}$ & $28(80)$ & $3(100)$ & $10(91)$ & $9(90)$ & $4(50)$ & $6(54)$ \\
\hline $\begin{array}{l}\text { Partial GH deficiency (\%) } \\
\text { Peak GH between 3-7 } \mu \mathrm{g} / \mathrm{L} \text { in } \\
\text { adults }\end{array}$ & $6(17)$ & $0(0)$ & $1(9)$ & $1(10)$ & $3(37.5)$ & 1(9) \\
\hline Hypothyroidism (\%) & $21(60)$ & $2(67)$ & $9(82)$ & $5(50)$ & $3(37.5)$ & $7(64)$ \\
\hline $\begin{array}{l}\text { Complete ACTH deficiency }(\%) \\
\text { peak cortisol under } 400 \mathrm{nmol} / \mathrm{L} \text { on } \\
\text { GST` }^{\star} \text { or ITT\# }\end{array}$ & $13(37)$ & $1(33)$ & $4(36)$ & $3(30)$ & $3(37.5)$ & $4(36)$ \\
\hline $\begin{array}{l}\text { Partial ACTH deficiency (\%) } \\
\text { Peak cortisol } 400-450 \mathrm{nmol} / \mathrm{L} \text { on } \\
\text { GST or } 400-550 \mathrm{nmol} / \mathrm{L} \text { on ITT }\end{array}$ & $3(8.5)$ & $0(0)$ & $0(0)$ & $1(10)$ & $1(12.5)$ & $1(9)$ \\
\hline Precocious puberty (\%) & $7(20)$ & $0(0)$ & $3(27)$ & $2(20)$ & $2(25)$ & $4(36)$ \\
\hline Delayed puberty (\%) & $1(2.8)$ & $0(0)$ & $1(9)$ & $0(0)$ & $0(0)$ & $0(0)$ \\
\hline Primary hypogonadism (\%) & $6(17)$ & $0(0)$ & $3(27)$ & $1(10)$ & $0(0)$ & $0(0)$ \\
\hline Secondary hypogonadism (\%) & $2(6)$ & $0(0)$ & $0(0)$ & $2(20)$ & $0(0)$ & $2(18)$ \\
\hline
\end{tabular}

PNET3 regimen: $\mathrm{RT}$ alone or $\mathrm{CT}$ followed by $\mathrm{RT}$, where the CT regimen compriseed four alternate cycles of vincristine, etoposide, carboplatin and vincristine, etoposide, cyclophosphamide .

CVC+RT: The standard regimen described by Packer where patients were treated with craniospinal local-boost RT and adjuvant CT with vincristine weekly during radiotherapy followed by eight ;6 weekly cycles of cisplatin, vincristine and CCNU (Lomustine) (CVC+RT regimen)

The UK "Baby Brain" regimen: children younger than 3 years, CT (vincristine, cyclophosphamide, cisplatin and etoposide) is employed post-operatively to delay or avoid RT

The total number of endocrine events was highest for patients receiving CVC+RT / Packer regimen at 2.8 events/patient, followed by 2.4 events/patient for those receiving PNET3 with chemotherapy and least in patients receiving PNET3 without chemo at 2 events/patient.

Prevalence of endocrine sequelae in medulloblastoma survivors is high and evolution of endocrine dysfunction can occur as late as 15 years from treatment completion, hence long term close monitoring of growth, puberty and gonadal function is essential. Endocrinopathies appear to be more prevalent in those treated with concomitant chemotherapy and radiotherapy. 